\section{Point on Early Neonatal Cardiovascular Changes and Hematocrit: Something to Study Further}

\section{Domenico Antonio Agostino ${ }^{1 *}$, Raphaël Thomasset ${ }^{2}$ and Ambrogio Di Paolo ${ }^{3}$}

${ }^{1}$ High Specialized Unit of Pediatric Cardiology - Complex Operative Unit of Neonatology and NICU, San Giovanni Addolorata Hospital, Rome, Italy

${ }^{2}$ Section of Gynecology and Obstetrics, Academic Department of Biomedicine \& Prevention and Clinical Department of Surgery, Tor Vergata University Hospital, Rome, Italy

${ }^{3}$ Complex Operative Unit of Neonatology and NICU, San Giovanni Addolorata Hospital, Rome, Italy

\section{Introdution}

Often the Hematocrit is a forgotten factor, it's correlation with other cardiovascular parameters is not considered or studied. The importance to considerate Hematocrit [1], during a research on a newborn, like a parameter of study is demonstrated by the laws of physics [2]. The most important law we consider is the Hagen-Poiseuille's law that shows the relationship between viscosity and hydraulic resistance:

$$
R=\frac{8 \eta d}{\pi r^{4}}
$$

Where $\eta$ is the viscosity, $\mathbf{d}$ the diameter of tube, $\mathbf{r}$ the radius of tube, $\mathbf{R}$ the resistance? Due to the small number of studies evaluating the impact of hematocrit on hydraulic resistance, in the different districts of circulation, until now we don't know the true weight of this parameter. The main districts in which more studies are needed are: cerebral, renal, cardiac, intestinal, pulmonary, and peripheral tissue/ microcirculation.

Different studies found a reduction in resistance parameters such as RI (Resistance Index) in cerebral circulation (middle cerebral artery or anterior cerebral artery) during the first hours of life but rarely the

*Corresponding author: Domenico Antonio Agostino, High Specialized Unit of Pediatric Cardiology - Complex Operative Unit of Neonatology and NICU, San Giovanni Addolorata Hospital, Rome, Italy; Tel: 00393286977243, E-mail: adomenicoantonio@gmail.com

Citation: Agostino DA, Thomasset R, Paolo AD (2019) Point on Early Neonatal Cardiovascular Changes and Hematocrit: Something to Study Further. J Non Invasive Vasc Invest 4: 016

Received: September 17, 2019; Accepted: September 18, 2019; Published: September 25, 2019

Copyright: @ 2019 Agostino DA, et al. This is an open-access article distributed under the terms of the Creative Commons Attribution License, which permits unrestricted use, distribution, and reproduction in any medium, provided the original author and source are credited. correlation is analyzed with hematocrit reduction, typically marked in this postnatal period [3-5]. The renal circulation has a significative change during these hours too: is well assessed that there is a initial slow reduction of RI and augmentation of peak systolic velocity in renal arteries during the first days and than a more rapid change in these perfusion indexes [5]. The measurement of cardiac parameters during the transitional period let us to understand both the pulmonary and systemic circulation changes. Studies evidenced a better left cardiac function and a reduction of right ventricular pressure seen indirectly by significative change of pulmonary mean acceleration, pulmonary acceleration time and other parameters $[2,3,6]$. Another hot topic is the patent ductus arteriosus in very preterm newborns and the influence of hematocrit on it, a rise in hematocrit may have a positive influence causing a reduction of left-to right shunt derived from a different pressure gradient between systemic and pulmonary circulation. If this mechanism is demonstrated by large studies, could be useful especially in very preterm newborns in which the immature left ventricle is not able to support such high blood flow coming from the patent ductus arteriosus [7]. A big open window that still needs to be studied in newborn physiology is the change of viscosity/hematocrit in peripheral tissues and microcirculation. Starting from large to capillary vessels in case of a Newtonian fluid there is no change in viscosity and so the Hagen-Poiseuille's law is valid, but in vivo circulation there is another phenomenon that happens. The Fåhraeus-Lindqvist effect is a progressive decline in apparent viscosity when blood flows through glass capillary tubes of diminishing radius. This effect is mainly effective in the arteriolar segments of the systemic vascular tree, where the majority of the total peripheral resistance resides and is actively regulated. Thus, the Fåhraeus-Lindqvist effect has been suggested to be an evolutionary trait that alleviates the impact of arteriolar vasoconstriction upon total peripheral resistance and thereby maintain local tissue perfusion at a relatively lower blood pressure [8].

\section{Conclusion}

In conclusion, the systemic cardiovascular evaluation in relation to changes in hematocrit is an essential approach to study newborns, especially during the first days of life when the hematocrit shows a significant decrease. The knowledge of the main key points of cardiovascular regulation and the pharmacology to act on them are the milestone of neonatologist. Further studies will be useful to help physicians make evidence-based decisions particularly in the management of very preterm newborns.

\section{References}

1. Sisson TRC, Lund CJ, Whalen LE, Telek A (1959) The blood volume of infants: I. The full-term infant in the first year of life. J Pediatr 55: 163-179.

2. Agostino DA, Thomasset R, Suzuki K, Versacci P, Guaglianone G, et al. (2019) Hematocrit : another important factor in systemic neonatal cardiovascular adaptation. J Pediatr Neonatal Individ Med 8: 1-9.

3. Noori S, Wlodaver A, Gottipati V, McCoy M, Schultz D, et al. (2012) Transitional changes in cardiac and cerebral hemodynamics in term neonates at birth. J Pediatr 160: 943-948. 
4. Forster DE, Koumoundouros E, Saxton V, Fedai G, Holberton J (2018) Cerebral blood flow velocities and cerebrovascular resistance in normal-term neonates in the first 72 hours. J Paediatr Child Health 54: 61-68.

5. Ilves P, Lintrop M, Talvik I, Muug K, Asser K, et al. (2008) Developmental Changes in Cerebral and Visceral Blood Flow Velocity in Healthy Neonates and Infants. J Ultrasound Med 27: 199-207.

6. Evans NJ, Archer LN (1990) Postnatal circulatory adaptation in healthy term and preterm neonates. Arch Dis Child 65: 24-26.
7. Lister G, Hellenbrand WE, Kleinman CS, Talner NS (1982) Physiologic Effects of Increasing Hemoglobin Concentration in Left-to-Right Shunting in Infants with Ventricular Septal Defects. N Engl J Med 306: 502-506.

8. Toksvang LN, Berg RM (2013) Using a classic paper by Robin Fåhraeus and Torsten Lindqvist to teach basic hemorheology. Adv Physiol Educ 37: $129-133$. 


\section{II \\ HERALD}

Journal of Anesthesia \& Clinical Care

Journal of Addiction \& Addictive Disorders

Advances in Microbiology Research

Advances in Industrial Biotechnology

Journal of Agronomy \& Agricultural Science

Journal of AIDS Clinical Research \& STDs

Journal of Alcoholism, Drug Abuse \& Substance Dependence

Journal of Allergy Disorders \& Therapy

Journal of Alternative, Complementary \& Integrative Medicine

Journal of Alzheimer's \& Neurodegenerative Diseases

Journal of Angiology \& Vascular Surgery

Journal of Animal Research \& Veterinary Science

Archives of Zoological Studies

Archives of Urology

Journal of Atmospheric \& Earth-Sciences

Journal of Aquaculture \& Fisheries

Journal of Biotech Research \& Biochemistry

Journal of Brain \& Neuroscience Research

Journal of Cancer Biology \& Treatment

Journal of Cardiology: Study \& Research

Journal of Cell Biology \& Cell Metabolism

Journal of Clinical Dermatology \& Therapy

Journal of Clinical Immunology \& Immunotherapy

Journal of Clinical Studies \& Medical Case Reports

Journal of Community Medicine \& Public Health Care

Current Trends: Medical \& Biological Engineering

Journal of Cytology \& Tissue Biology

Journal of Dentistry: Oral Health \& Cosmesis

Journal of Diabetes \& Metabolic Disorders

Journal of Dairy Research \& Technology

Journal of Emergency Medicine Trauma \& Surgical Care

Journal of Environmental Science: Current Research

Journal of Food Science \& Nutrition

Journal of Forensic, Legal \& Investigative Sciences

Journal of Gastroenterology \& Hepatology Research

Journal of Gerontology \& Geriatric Medicine

Journal of Genetics \& Genomic Sciences

Journal of Hematology, Blood Transfusion \& Disorders

Journal of Human Endocrinology

Journal of Hospice \& Palliative Medical Care

Journal of Internal Medicine \& Primary Healthcare

Journal of Infectious \& Non Infectious Diseases

Journal of Light \& Laser: Current Trends

Journal of Modern Chemical Sciences

Journal of Medicine: Study \& Research

Journal of Nanotechnology: Nanomedicine \& Nanobiotechnology

Journal of Neonatology \& Clinical Pediatrics

Journal of Nephrology \& Renal Therapy

Journal of Non Invasive Vascular Investigation

Journal of Nuclear Medicine, Radiology \& Radiation Therapy

Journal of Obesity \& Weight Loss

Journal of Orthopedic Research \& Physiotherapy

Journal of Otolaryngology, Head \& Neck Surgery

Journal of Protein Research \& Bioinformatics

Journal of Pathology Clinical \& Medical Research

Journal of Pharmacology, Pharmaceutics \& Pharmacovigilance

Journal of Physical Medicine, Rehabilitation \& Disabilities

Journal of Plant Science: Current Research

Journal of Psychiatry, Depression \& Anxiety

Journal of Pulmonary Medicine \& Respiratory Research

Journal of Practical \& Professional Nursing

Journal of Reproductive Medicine, Gynaecology \& Obstetrics

Journal of Stem Cells Research, Development \& Therapy

Journal of Surgery: Current Trends \& Innovations

Journal of Toxicology: Current Research

Journal of Translational Science and Research

Trends in Anatomy \& Physiology

Journal of Vaccines Research \& Vaccination

Journal of Virology \& Antivirals

Archives of Surgery and Surgical Education

Sports Medicine and Injury Care Journal

International Journal of Case Reports and Therapeutic Studies

Journal of Ecology Research and Conservation Biology 